\title{
Reproduction of human capital in Bulgaria1
}

\begin{abstract}
With the development of the global economy, the extent of the influence of different factors of economic growth changes. In the conditions of the newly-forming knowledge economy, the generation, exchange and implementation of learning has become the main engine of economic development. In these circumstances, the European Union aims (under the Lisbon strategy) to become the most competitive, dynamic, knowledge-based economy, with more and better employment opportunities and higher social cohesion. A member state of the EU, Bulgaria has to meet European standards and requirements for development, including those concerning human capital. All these determine the importance of the problems of human capital, of the necessity of investment in its development, of the efficiency of its use and of the need for a targeted state strategy and policy in this sphere. The subject investigated in this article is the process of the reproduction of human capital in Bulgaria in its economic perspective, with the accent on education. Other aspects, such as health status and migration processes, are not the subjects of the investigation herein.
\end{abstract}

Keywords: human capital, active labour market policy, migration, education system and policy, lifelong learning, technological development, knowledge economy, EU standards, labour productivity,

\section{Main theoretical concepts concerning human capital}

An analytical overview of the economic literature, of the range of theoretical and empirical studies into the essence and the evolution of the theory of human capital, allows us to make some general conclusions about the concepts that are at work.

With the socio-economic development of society, the role of learning as a factor of growth becomes more important. In parallel, the theory of human capital also undergoes evolution. The concept of human capital is enriched; the methods and models for its investigation become better; the set of used indices broadens; and the studies of the factors, interactions, effects, role and importance of human capital for growth, competitiveness and wealth become wider. At first, labour was treated as just one of the factors of growth and workers as a 'collective mass' the skills and knowledge of which were not taken into consideration.

With the development of the economy and the speeding-up of its transformations, the role of human capital has grown. Today, when we are entering the age of the knowledge economy, human capital is becoming the main engine of growth. The large num-

1 This paper presents some of the results of a complex study of the reproduction cycle of human capital in Bulgaria. 
ber of theoretical and empirical studies proves the significant contribution of education to economic growth and of human capital to the creation and implementation of scientific and technological achievement. Economic practice shows that developed countries allocate more and more resources to investment in intangible assets, one of the main elements of which is human capital.

The results of this study show that, with the expansion and extension of theoretical and empirical investigation, more proof of the increasing role and importance of learning has been found. At present, the accent is put not only on the level but also on the quality of learning and skills and on the abilities of people to put them into practice.

The theory of human capital, as with a number of other theories, is subject to criticism. For example, its model does not reflect some factors, such as the quality of education and training, the existence of a number of incomparable educational products, differences in the capabilities of individuals, etc. These imperfections, however, depend to a great extent on the under-development of the system of evaluation and measurement. Learning is unique because of its intangible nature, which creates difficulties for its measurement.

In the economic literature, human capital is defined as an aggregate of the learning and skills that lead to an increase in productivity and to social and economic welfare. In order that the accumulated learning and skills do indeed lead to increased productivity, they should be utilised, i.e. applied in practice. From an economic point of view, human capital exists as potential up to the moment when it enters the production process. In other words, the economic development of society depends to a great extent on human capital being available and functioning, as well as on its quality and the effectiveness of its use.

Starting from that basis, a differentiation could be made between the 'level' and the 'quality' of human capital from an economic perspective. If the level of human capital could be defined in general as the acquired level of education (and skills), its quality could be defined as a combination of essential characteristics - learning, skills and experience; the extent of their development; and the effects of their use and practical application. All these determine the scale of the increase in their economic importance and of productivity, flexibility and adaptability, with all the subsequent economic and social impacts. The higher the quality of human capital (i.e. the higher the level of its education and skill level and the richer its experience; the higher the quality of acquired learning and the effectiveness of its use), the greater is its economic importance.

The study of a number of investigations of human capital allows the identification of the logical relationships and interdependence between the acquisition of learning (the formation of human capital), the level and quality of acquired learning and skills (the status of human capital) and the application of that learning for the achievement of economic growth and technological development (the use of human capital). These could be defined as three phases of one cycle - the cycle of the reproduction of human capital. The unity of these three phases turns each of them at one and the same time into an influencing factor and a result of the influence of the other phases. This logical interrelationship and determination is the basis of the analysis of the status and the systematisation of directions for the development of human capital in Bulgaria which 
appear in this article. The logical relationships and interdependence are presented in Chart 1 but could be summarised as follows:

- education is the system in which learning and skills are created and disseminated. The role of training is also important. The development and improvement, as well as the restoration, of human learning should be a continuous process. This is necessary because of the speeded-up structural and technological changes taking place in the economy

- migration processes could favour or hamper access to education and training, and could also lead to the so-called 'brain drain' or 'brain gain'

- healthcare is the system which sustains and restores the physical and psychological status and health of people. The better the health status, the better the acquisition of learning and its use in the work process. Simultaneously, the higher the educational level of people, the better are their abilities and the higher are their efforts in maintaining their health status in a good condition

- the demographic situation and the changes which can be characterised by a low birth rate and an ageing of the population (in developed countries) lead to a limitation on human resources and, through that, on the availability of human capital as well as on the potential for its formation.

All these processes - education and training, healthcare, migration and demographic changes - form the human capital of a country and determine its level and quality. At the same time, the continuously changing requirements of the economy and of society, and the possibilities for improving human capital, have a reverse effect and lead to respective changes in them.

In connection with all that was said above, state policy on the development of human capital could not be limited only to its formation in the system of education. Proceeding from the adopted methodology for investigating human capital - as a cycle consisting of three phases (or components) - this policy should be complex and should cover all phases of the cycle. It should be directed towards the different factors which form and have an influence on human capital.

Taking into account the most important public (economic and social) effects of education, as well as a critical analysis of the main theoretical concepts on the role of the state in the formation of human capital (including the contrary opinions in polemics on the role of the state in general), it could be said that there is a requirement for considerable state intervention as well as for the adoption of an active role in order to:

- maximise the public benefits of education

- minimise the market failures

- increase the quality of economic development

- raise living standards and restrict poverty

- decrease discrimination against some groups of the population; etc.

The main directions of such a complex policy (the points outlined here are developed further below) are: 


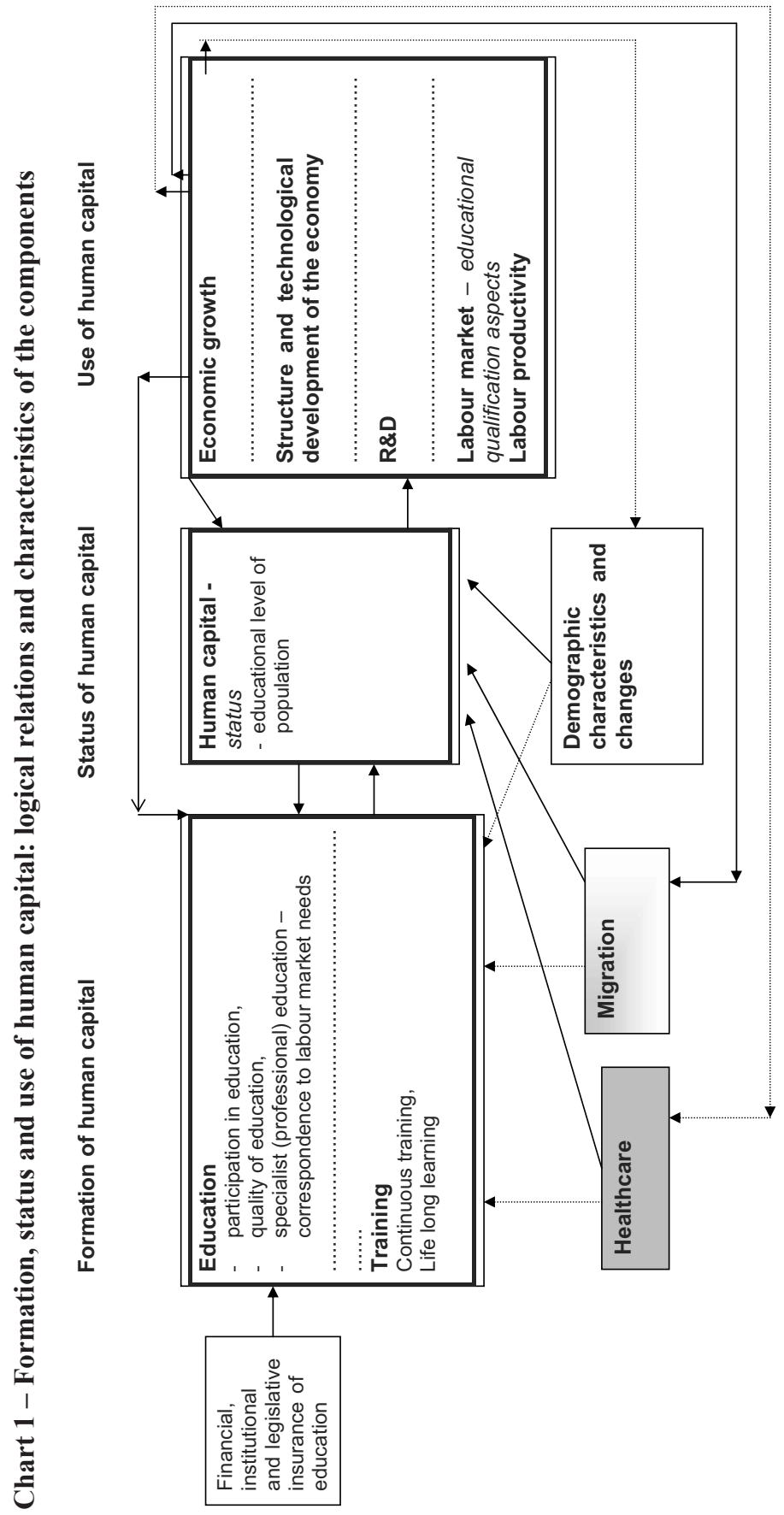


- the provision and maintenance of macroeconomic stability and fast and sustainable growth

- promotion of the development of medium- and high-technology branches and production, as well as of technical, technological and scientific development

- active labour market policy providing a higher level of balance between labour supply and demand, including from the educational-professional perspective, and adequately assisting in the professional upskilling and training of employees and the unemployed

- active demographic policy

- adequate migration policy

- health policy

- education policy.

It has to be taken into account that, together with these significant points, of importance for the development of human capital is also the improvement of the set of regional, tax, credit and budgetary, etc. policies.

\section{Formation of human capital in Bulgaria}

The analysis of the status of and the main changes in the formation of human capital in Bulgaria in the system of education and training, and a comparison with the main indicators highlighted in European documents for the development of this sphere, outlines the important areas in which Bulgaria is lagging behind European criteria and direction, and identifies the main problems for the formation of human capital in the country.

In accordance with the methodology of this study, the main direction of analysis is focused on:

1. the general status of and trends in the formation of human capital, including participation in and access to education, the qualitative aspects of education, specialist (professional) education, professional skills and lifelong learning

2. the existence of the necessary conditions for the adequate functioning of the systems of education and training, including legislation and institutional and financial support (provision).

The results of our analysis show some positive changes in the sphere of education and training which are favourable to the formation of human capital in the country. These are:

- growth in net enrolment rates at all levels of education (with the exception of preschool education)

- increase in the mobility of students

- improvements in the legislative basis which adapt it to the directions and goals of the EU in this area

- institutional improvements, etc.

The result of these changes has been that some of the quantitative indicators have been improved, including compared to the EU average.

Together with all these positive changes, there are substantial problems regarding the present and future formation of human capital. These lead to a number of negative 
characteristics concerning the present status of the issue as well as to imperfections in its use.

The main problems may be summarised in the following sub-sections.

\section{Participation in and access to education}

Analysis and assessment of the number of pupils and students and net enrolment rates in education show essential problems concerning the level of newly-forming human capital. There is a lagging behind EU target indicators with respect to the participation of the population in education, which is most significant in the sphere of secondary education (almost one-fifth of young people ${ }^{2}$ in the country do not complete secondary education and there has been no trend toward a decrease in this proportion in the last few years). There is also a lagging behind in the sphere of higher education as well as in that of compulsory education (almost one-sixth of children do not participate in lower secondary education). Drop-out rates are still high and do not decrease even in compulsory levels of education. This is true especially for children from families with low incomes, from rural and distant areas and from minority groups. This negative phenomenon is connected with the existing limits in access to education. ${ }^{3}$ Problems concerning participation in and access to education are evidence that there are significant gaps and imperfections in the formation of human capital in the country.

Sizable, and also not decreasing, are discrepancies in access to education from a regional perspective, as well as by social groups of the population and, to some extent, by gender. Despite the constitution of the country, where it is said that there is a right of equal access to education, there are conditions why rights are not equal and policy has still not eliminated them.

The high percentage of young people with an incomplete secondary education and, at the same time, the rapidly growing number of doctorate students, as well as the significant discrepancies between household expenditures on education in accordance with incomes, are indicators for a stratification of the population in relation to educational attainment and access to education.

The problems of participation in and access to education do not concern only separate groups of the population. They determine a lower level of human capital in the country as a whole, with all its negative consequences for economic development. This in turn requires new resources for overcoming such imperfections. All these lead to one further loss for society caused by the ineffective use of public resources for the formation and development of human capital.

2 Of the 18-24 year age group.

3 This is a question not of administrative restrictions on access to education but of such posed by the socio-economic and cultural-historical situation in the country. 
Figure 1 - Early school leavers (\% of the population of the 18-24 age group)

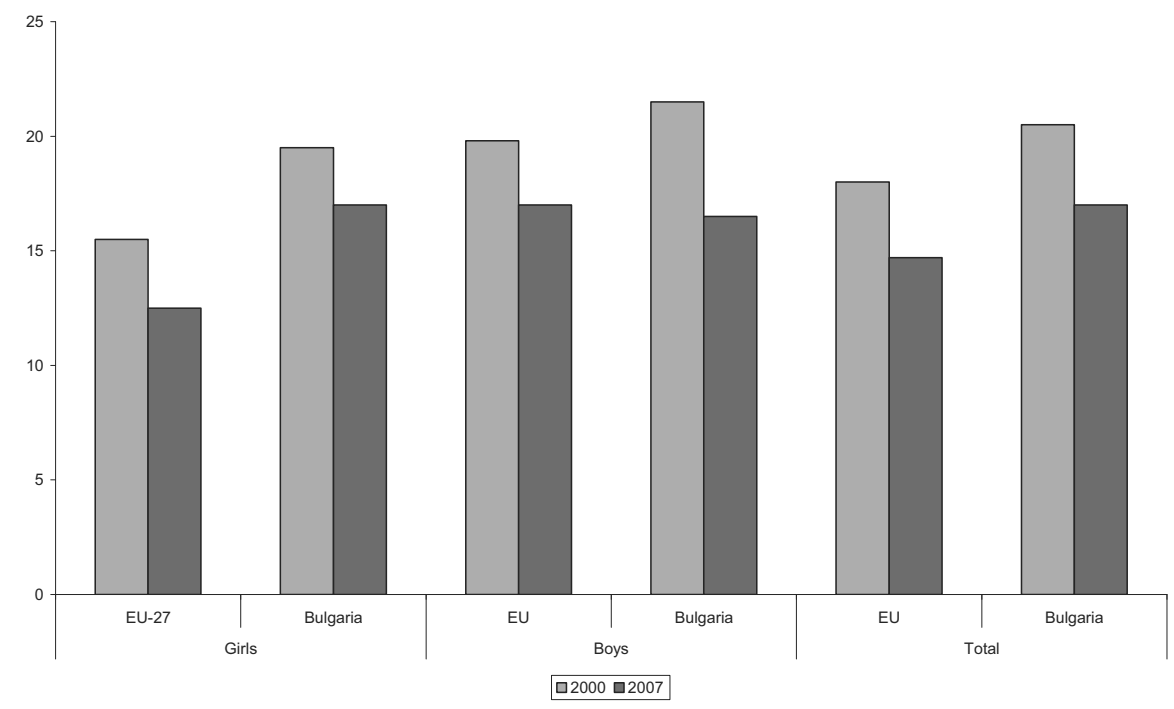

Data for Bulgaria are for 2001 and 2007

Source: Eurostat

\section{Quality of education}

There is a very unfavourable tendency concerning the decrease in the quality of education in Bulgaria. This is the point on which the quality of the newly-forming human capital depends, as does the efficiency of public expenditure on education and the perspectives on raising the competitiveness of the economy. It not only lags behind average international indicators but is also decreased compared to previous years in the country. Important premises for this situation are problems in the fields of: material and technical foundation; equipment and the implementation of ICT in education; the modernisation of programmes; profiles and methods of training and of training materials; the practical training of pupils and students; changes in the age structure and the system of the improvement of the skills of teachers and lecturers; development of standards, criteria and indicators for the assessment and control of quality in education; the efficiency of the education system; the effects of educational policy (guaranteed by the legislative basis); etc. 
Figure 2 - Changes in the assessment of $8^{\text {th }}$ grade pupils in mathematics and science (points score)

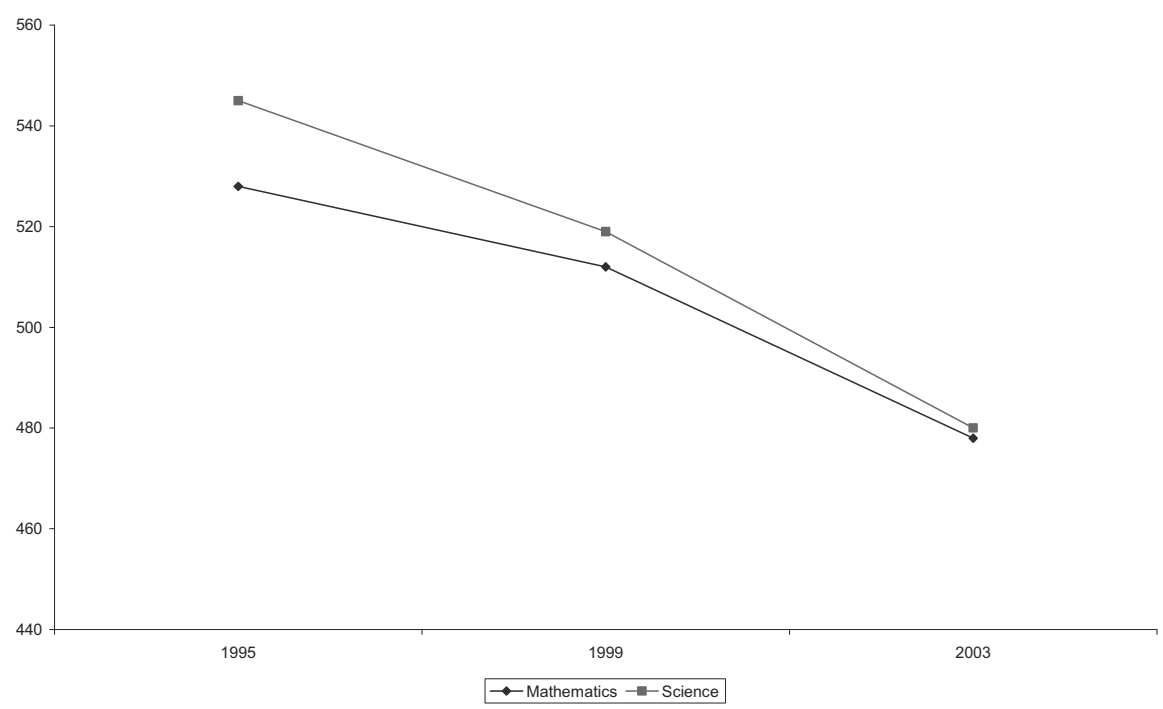

Source: TIMSS

There is still no substantial progress regarding the improvement of the efficiency of the education system. The main premises for this are the absence of national priorities for the development of the economy and of standards and indicators for efficiency and the assessment of quality. Relations with the social partners, and especially with employers, are not well-developed; the practical training of pupils and students in real conditions is insufficient; professional orientation is only now being re-launched; there is no system for investigating the requirements of the labour market; the system of control is not developed to the necessary extent; decentralisation is not finalised; etc.

There has been some progress concerning the mobility of students, especially in the rapidly growing number of Bulgarian students going to study abroad, but there is also a lagging behind in the number of foreign students studying in Bulgaria. This tendency has positive as well as potentially negative consequences - i.e. the risk of the loss at a high level of newly-forming human capital.

\section{Education for profession}

An investigation into education for profession describes a lagging behind compared to European trends and the requirements of the knowledge economy (for example, there is such a lag in the education of students in the field of mathematics, science and technology in Bulgaria). 
Figure 3 - Students and graduates in science, mathematics and computer technologies

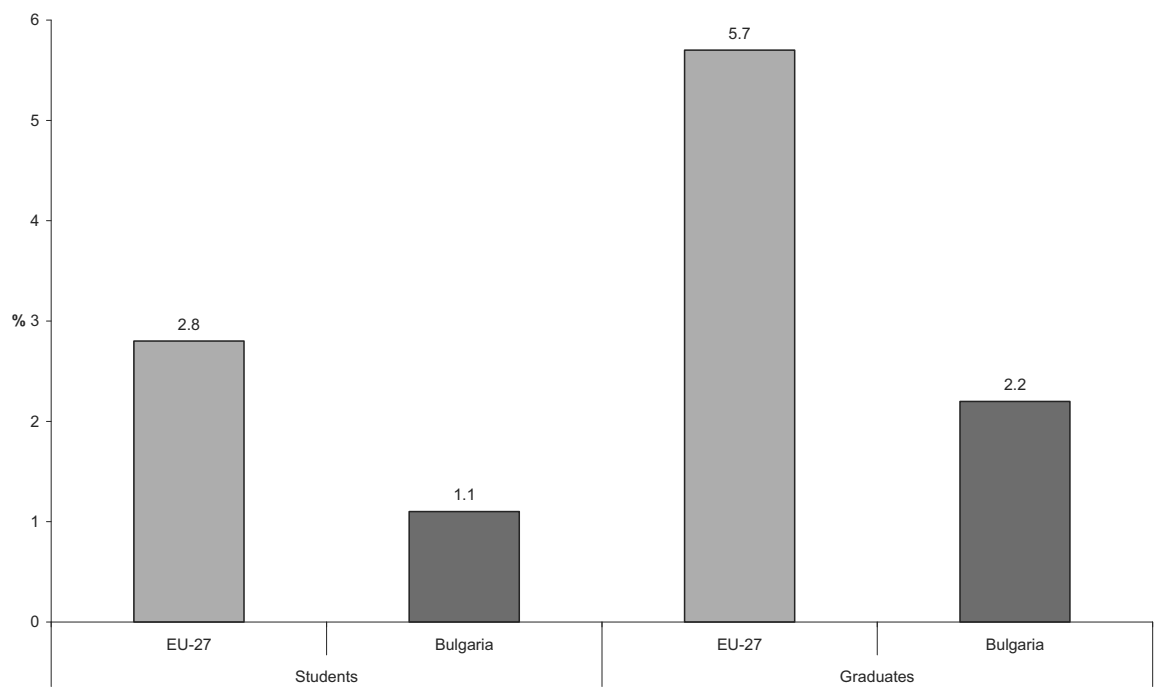

Students as \% of the population of the 20-29 age group

Graduates per 1000 people of the population of the 20-29 age group

Source: Eurostat (2008) Science, technology and innovation in Europe

A comparison between education for profession and the requirements of the economy of the country allows us to identify some other disparities in this area. (This direction of analysis has a relationship with the level and the quality of newly-forming human capital.) The necessary extent of correspondence between education and the requirements of the economy has not yet been achieved. The negative effects of this disparity are related to the ineffective use of public resources in the system of education, leading to the formation of human capital with inadequate learning in comparison to the requirements, as well as with a limitation of the possibilities for accelerated economic growth.

Analysis shows that important preconditions leading to the problems that exist in education for profession are the weak relations between education institutions and employers; insufficient information; slow adaptation of the education system to the requirements of the knowledge economy; etc.

\section{Participation in training}

Investigation into the second element of the system of the formation of human capital - training - shows that participation in professional training, and especially in lifelong learning, is still very limited. This demonstrates the existence of important gaps in, and 
unrealised possibilities for, improvements in the formation, development and adaptation, quality and restoration of human capital in the country.

The results from this study prove that the share of participants in lifelong learning is minimal and that the extent of lagging behind EU goals and indicators is significant.

Figure 4 - Participation of the population in lifelong learning (\% of population in the 25-64 age group participating in education and training)

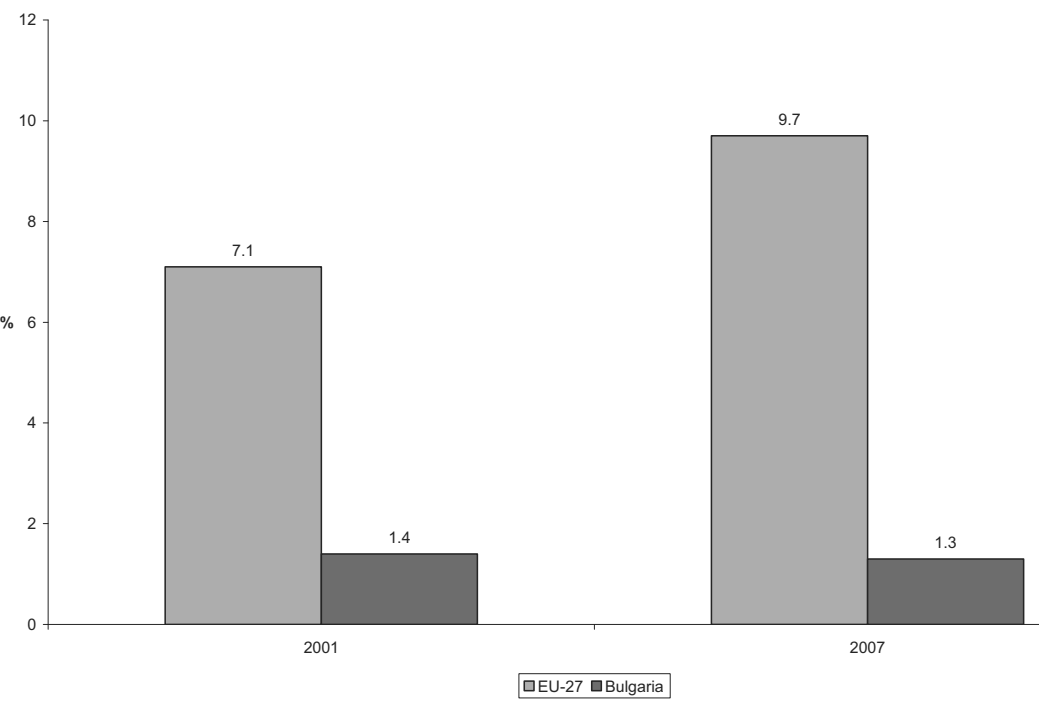

Source: Eurostat

There is a significant difference in informal education, especially from the regional aspect, and we may observe an important lagging behind in participation in lifelong learning by young people in Bulgaria compared to average European indicators. 
Figure 5 - Participation of the population in lifelong learning by age group (\%)

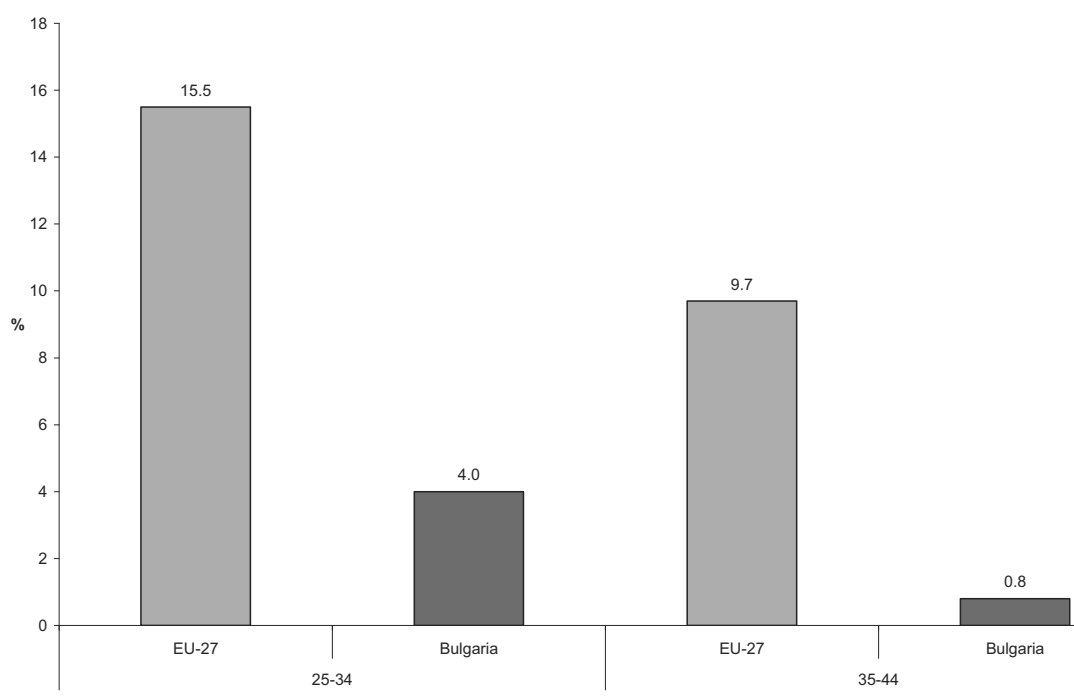

Source: Eurostat; data for 2006

The existing differences in the acquisition and improvement of the learning of separate groups of the population form another of the continuing challenges to the raising of the general level and quality of human capital in the country (and also a pre-condition for Bulgaria's future lagging behind in this area).

\section{Legislative, institutional and financial support for education and training}

An analysis of the status and changes in the level of legislative, institutional and financial support for education and training, as important and necessary conditions for their effective and qualitative functioning towards the production and dissemination of learning, and consequently for the formation of the level and quality of human capital, shows the following main imperfections and problems.

The legislative basis of the systems is, to a great extent, adapted to EU requirements. There are, however, still a number of imperfections, such as:

- incompleteness

- absence of continuity and sustainability

- insufficient level of synchronisation and mutuality between different legislative documents

- problems in partnerships between administrative bodies

- insufficient preparation for the practical implementation of the legislative basis

- insufficiently prepared decentralisation

- under-developed system of stimuli and mechanisms for the promotion of investment in education 
- absence of standards and indicators of quality and efficiency

- absence of a system for professional orientation

- insufficient regulation and implementation of practical training and practice in employers

- incomplete system of state standards

- ineffective system of training for teachers and lecturers and of a guarantee of their social status.

The institutional structure has been set up. The problems here come mainly from: its insufficient effectiveness; poor connections between the different institutions and structures (horizontal and vertical); and inactive interaction with the social partners, especially at the regional and local levels; etc.

The financial support provided is insufficient. Resources are limited and insufficient for the realisation of the reform, as well as for the necessary renovation of the material and technical equipment of educational institutions and for raising the quality of the education process.

There are a number of gaps, imperfections and unused possibilities for the formation of the level and quality of human capital in the country, both in its quantitative and its qualitative aspects. The outlined imperfections in this area determine a number of problems and a falling behind the EU concerning the main qualitative characteristics and use of human capital in Bulgaria.

\section{Status of human capital}

An analysis of the status of human capital in the country is directed towards its quantitative and main qualitative characteristics. The indicators which are used for an assessment of the status of human capital in its qualitative aspect are connected mainly to the educational characteristics of the population, and of the labour force in particular as far as it is functioning, and not newly-forming or inactive human capital.

On the basis of an analysis of the educational characteristics of the population (both as a whole and of different groups, including age, social group, region, etc.), an assessment of the status of human capital could be made - of the existing imperfections and of the potential risks of its future obsolescence.

The labour force, or the current economically active population, is that part of the population that furnishes a supply of labour for the production of goods and services. People not in the labour force (or the current economically inactive population) possess different kinds of learning but, for one reason or another, do not apply or offer them. The results of the investigation of the educational characteristics of these categories of people allow us to make a more concrete assessment of the status of the functioning of human capital, as well as of that part of the population which does not apply its learning (non-functioning human capital). This is also in direct connection with the problems in the use of human capital in the country which are examined below.

Unrealised human capital is a double loss for society. There is a loss coming from the investment made in its formation, while there is also a loss, in terms of missed benefits, concerning the possibilities for economic and technological development. 
The results from the analysis of the status of human capital in the country show a comparatively good level concerning the educational structure of the population (and in particular of the labour force) and its changes. According to this indicator, Bulgaria is close to the average European level. Some quantitative and qualitative characteristics, however, also describe the existence of important problems.

There are purely quantitative limits created by the difficult demographic situation in the country, by the deterioration in the age structure of the population and by some unfavourable prognoses, including compared to those for the EU as a whole. This situation requires a rise in the level and the quality of human capital in order to maintain and increase productivity, and also an achievement of a higher level of use of the human capital available.

\section{Figure 6-Differences between the main demographic indicators for Bulgaria and the $\mathrm{EU}-27$ average (in percentage points)}

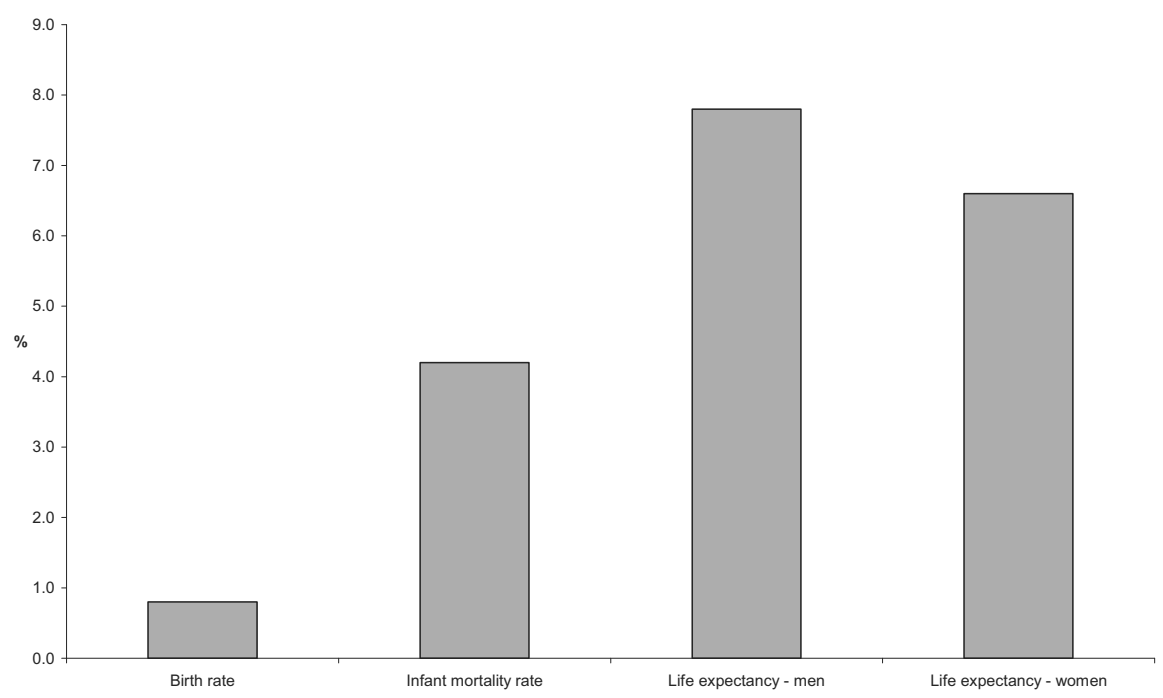

Source: Eurostat, data for 2006

Despite the existing stability in emigration flows during the last few years, Bulgaria has lost a part of its human capital. The main part of potential emigrants at present consists of young and well-educated people, which represents a possible risk of subsequent losses of human capital for the country (especially given its high level and its newly-formed status). These phenomena and trends direct attention to the need to increase the level and the quality of that part of human capital which is available and remaining in the country.

With the outlined improvements in the educational structure of the population, and in particular of the labour force, there have to be taken into account the following important points: 
a) the improvement in the educational structure of the population over 55 years of age is, to a great extent, due to the purely mechanical movement of some lower educated people into a higher age group, as well as to the movement of some highly-educated people from lower age groups into this one. (Indicative in this respect is the almost unimportant participation of people from this age group in lifelong learning, i.e. in formal and informal education)

b) there is a lag in the group of young people with secondary education, which is a premise for the potential stratification of the population with a view to educational preparation as well as for a possible future deterioration of the educational structure

c) there is also a lag in the group of people with the highest level of education, i.e. of a high level of human capital, compared to EU average indicators (although it is not particularly sizable). At the same time, more young people are studying abroad. This is a positive phenomenon with a view to increasing mobility, but it also contains a risk that highly-educated young people will not return to the country, representing a loss of human capital. (A number of inquiries show that the return of these people depends, in their own view, on the improvement of socio-economic conditions and living standards in the country.)

d) the quality of education is decreasing. This process shows that, even if there are some improvements in the quantitative aspect, in the qualitative aspect there are significant risks of a worsening of the status of human capital in Bulgaria.

Figure 7 - Structure of the population aged 15 years and over by education (\%)

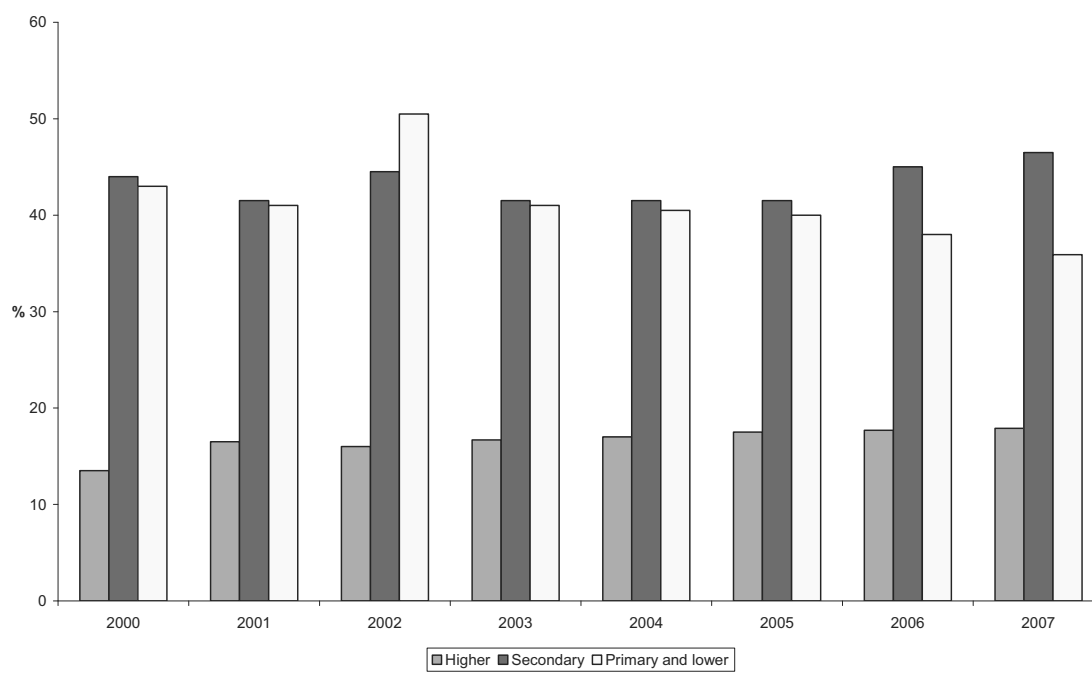

Source: National Statistical Institute Employment and unemployment for the corresponding years

Groups of the population exhibit significant differences in educational attainment, because of the limits on access to education (due to different reasons), and thus have a 
lower educational level than the average. This has an unfavourable influence upon the general level and quality of human capital in the country. These negative elements of the characteristic of the status of human capital result, to a great extent, from the problems in its formation outlined above. At the same time, they exert an influence on the possibilities and the extent of the use of human capital, on economic and technological development and on labour productivity and growth.

Figure 8 - Population with higher education (per 100 people of the population in the 25-64 age group)

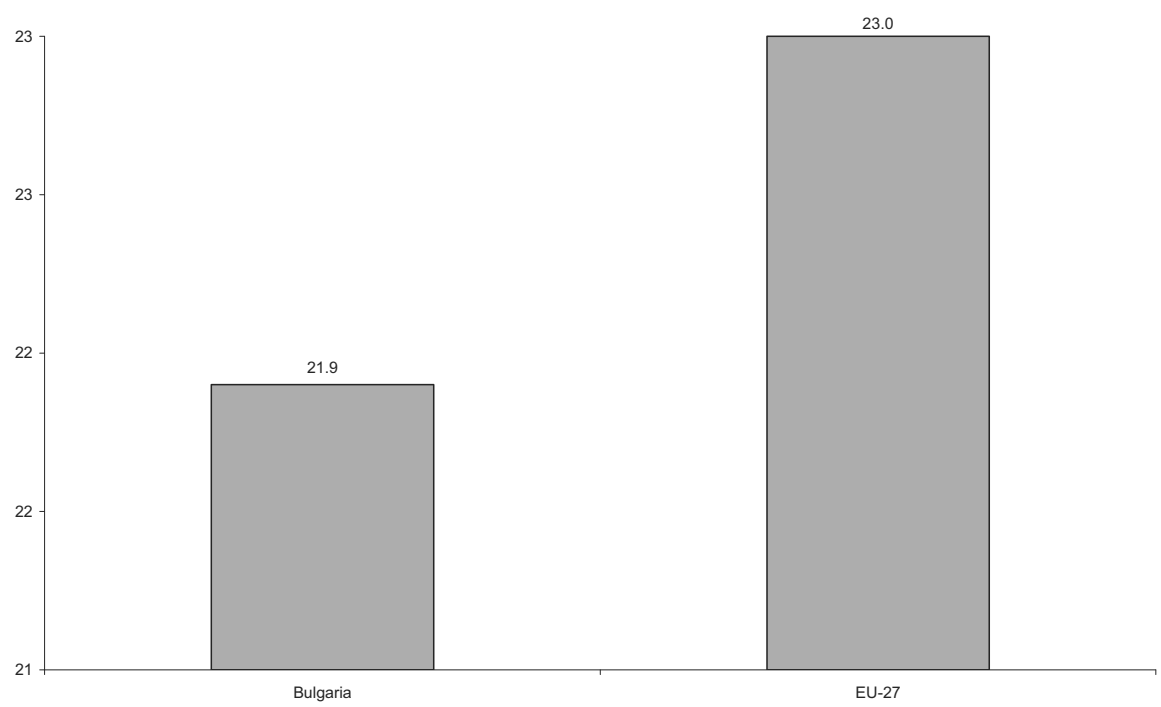

Source: European innovation scoreboard, 2007 (data for 2006) 
Figure 9 - Structure of the population 15 years of age and over by place of residence and education $(\%)$

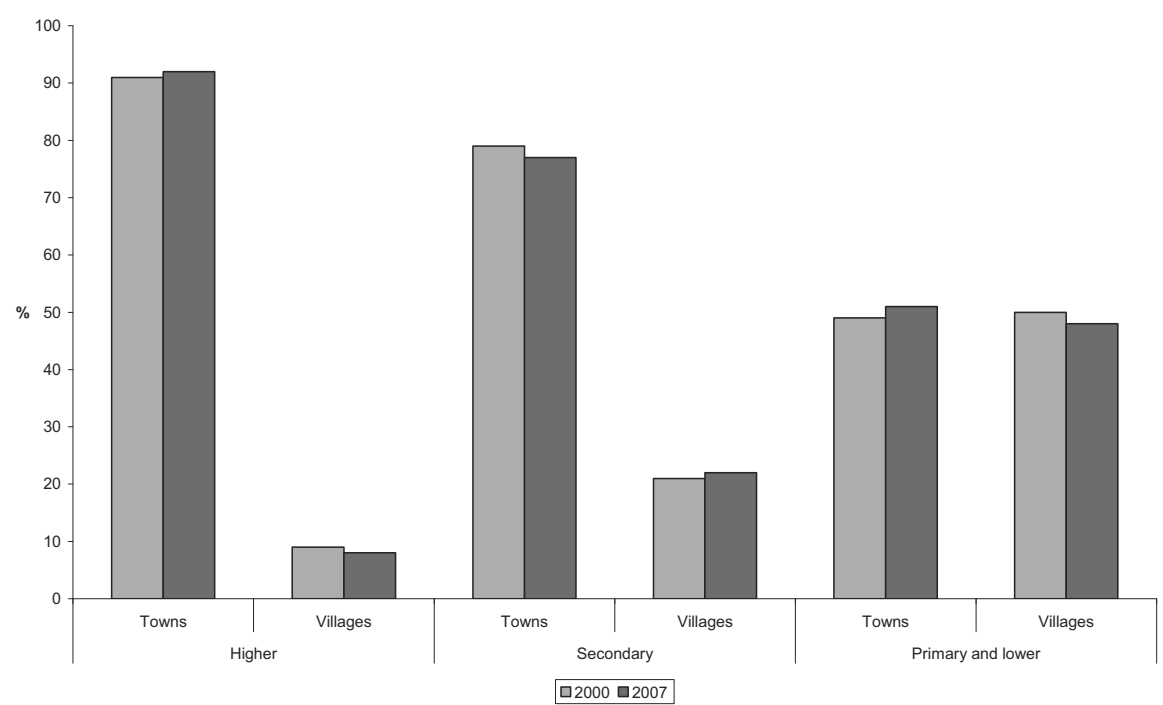

Source: National Statistical Institute Employment and unemployment for the respective years

The problems with the education of young people, i.e. newly-formed human capital, are alarming. The share of the younger population has decreased constantly during the last few years and, from the purely quantitative aspect, its influence on the average level of human capital in the country is smaller. However, young people are the future and not only the level but also the quality of human capital in some perspective depend on them. They must possess greater learning, and of a higher quality, firstly because of their own decreasing number but also because of the contemporary needs and requirements of socio-economic development and of the knowledge economy.

Not less problematic is the lagging behind in the share of the highly-educated population, i.e. of high-level human capital, as well as the non-application of learning in one part of it. 
Figure 10 - Structure of the population by age group and level of education (\%)

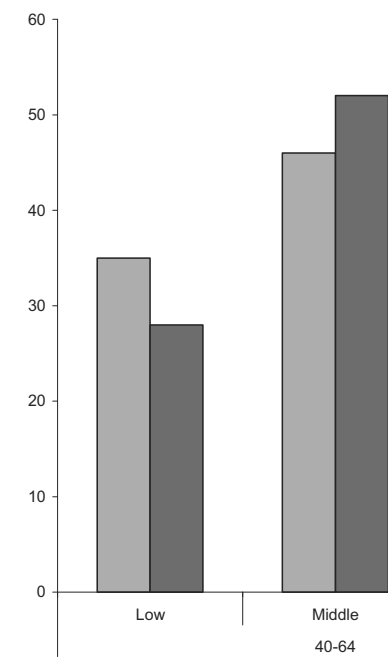

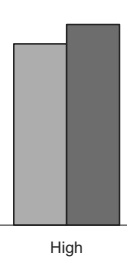

口EU-27 口Bulgaria

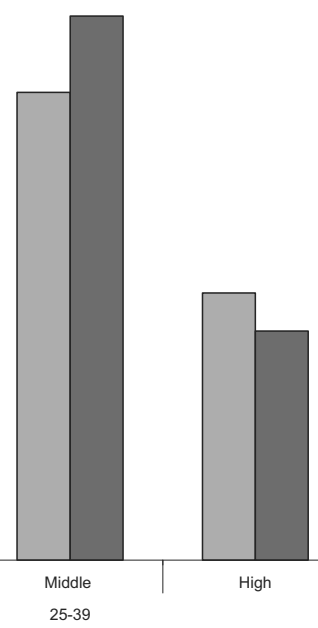

Source: Eurostat, Cultural statistics, 2007

The unfavourable trends in the educational structure of the labour force and of those not in the labour force which have been outlined here show that there is learning, i.e. formed human capital, which does not correspond to the necessities of the economy and/or is of lower quality compared to what is required. These hinder the realisation of such learning in the market and lead to important losses and unused benefits from the point of view both of human capital formation and of that of economic growth and technological development.

The results of this analysis show also the following problems:

a) a lagging behind as regards the existence and use of high level human capital (people with higher education)

b) the existence of human capital of a relatively high level which does not function and is not applying its knowledge base.

The impossibility of applying learning amongst one part of human capital in the country, or otherwise the unwillingness to do so, leads to important losses for individuals as well as for society as a whole.

These problems are related, on the one hand, to the formation of human capital, its adequacy and the quality of the learning acquired; and, on the other hand, to its use. It is hard to apply learning which does not correspond to the requirements of the economy and/or is of lower quality.

A negative phenomenon in the characteristic of the status of human capital in Bulgaria is the shorter median duration of education in comparison with the average for the EU. This shorter process is a premise for the acquisition of a smaller amount of 
learning (i.e. for a lower level of human capital), except when it is compensated for by a higher quality and intensity. The results of international comparison as well as from this study show that the quality of education in Bulgaria is decreasing and is already below the average indicator for other countries. A higher intensity of training (such as is not observed within the country) could also have negative effects, including the creation of the conditions for the more realistic acquisition of knowledge, i.e. for a lower level of acquired knowledge.

\section{Use of human capital}

Analysis and assessment of the use of human capital may also be made in both it quantitative and qualitative aspects. This is a process with many perspectives which is difficult to cover and assess in the round. For the needs of this part of the study, the following indicators, which outline the most important directions of the use of human capital, have been selected and used. ${ }^{4}$

- economic growth, which creates the possibilities for the increase of employment and, thereafter, for the fuller use of human capital.

In order to assess in a qualitative respect the adequacy and competitiveness of the use of human capital, it is necessary to investigate the directions of structural changes in the economy and of the state of its technical and technological development. This is the way to define whether the education of the population and of the labour force corresponds to the structural changes and whether the acquired knowledge could be used to create and apply new technologies and techniques (these are the conditions for the improvement of competitiveness and for the building of the knowledge economy).

- structural changes in the economy, which impose a new requirement on the type and the level of knowledge required and which define new directions for the use of human capital

- technological directions for the development of the economy: the higher this is, the bigger the demand and the requirements for quality, high level human capital. This is a main precondition for the improvement of the competitiveness of the economy

- educational aspects of labour demand and supply, where a higher level of correspondence in this area presumes the existence of adequate human capital, given the requirements of the economy and also the higher level of its utilisation.

The study of the labour market from this viewpoint allows a more profound investigation of the use of human capital from the perspective of the correspondence between existing and newly-forming human capital and the requirements of the market for different types of knowledge and skills; an enriched assessment of the use of this capital and of its existing potential and discrepancies; and, at the same time, it outlines the gaps and the imperfections in its formation.

- labour productivity is one of the most important indicators of the level and efficiency of the use of human capital (and, at the same time, it is an important factor in improving competitiveness and in achieving sustainable economic growth).

4 Chosen are those indicators which could be measured and for which there is sufficient statistical information. 
Results from the analysis of the use of human capital allow us to make the following important conclusions.

The maintenance of relatively high rates of growth during the last few years and the stabilisation of the economy and of its structural changes create favourable conditions for the better use of human capital in the country (indicative of which are the increasing rates of economic activity and of employment). Together with this positive trend, some important problems may be observed.

\section{Figure 11 - Real GDP growth rates (percentage change in relation to previous} year)

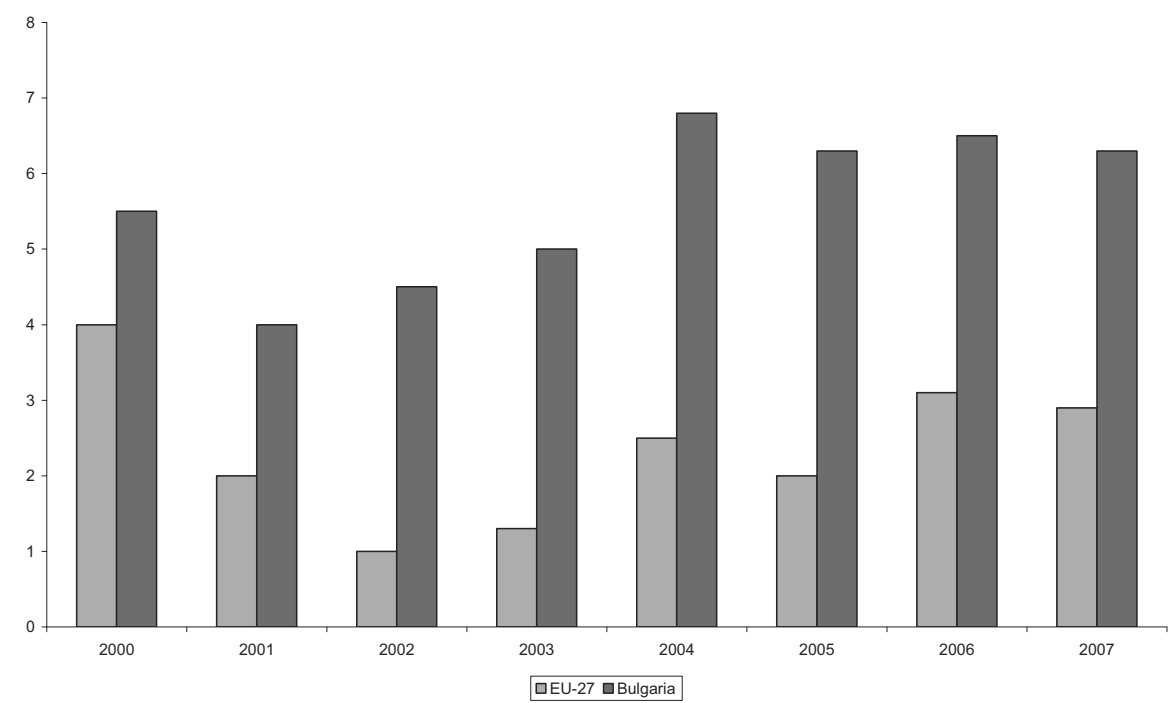

Source: Eurostat

The maintenance of sustainable and high rates of growth, as well as increasing investment activity, favour the fuller use of human capital. It has to be taken into account, however, that Bulgaria is starting from a lower level (compared to the EU) and that it remains significantly behind the average level for the EU.

The significant changes in the structure of the economy (which lead to the creation of some new professions and to the reduction of some others) pose new requirements on learning and skills, and on human capital. The satisfaction of these demands requires time and resources. The continuity of this process, which has not been realised to the extent necessary, depends on what is required - whether it is restoration, improvement or the acquisition of new learning and skills. 
Bulgaria lags behind in the development of middle- and high technology sectors and production, as well as in all the main groups of indicators which concern scientific, technical and innovation activity ${ }^{5}$ compared to the EU average.

\section{Figure 12 - Share of those employed in R\&D in the total number of employed people $(\%)-2004$}
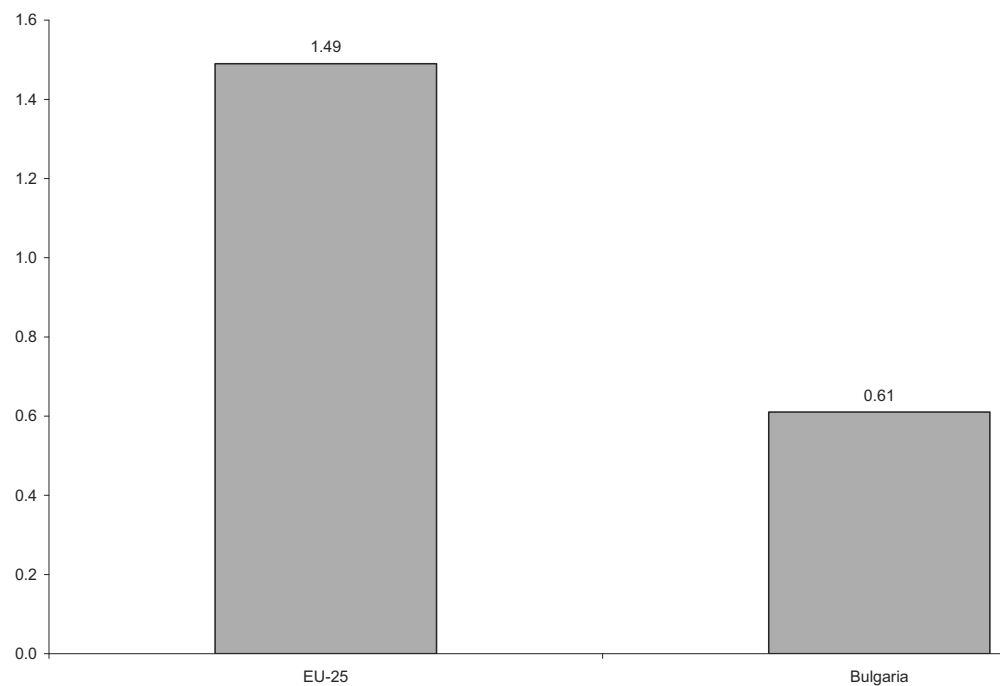

Source: Eurostat, "Science, technology and innovation in Europe", 2007

This means that human capital is not being used adequately in accordance with the requirements of the knowledge economy. This lagging behind in technological development points at two important problems:

1. a non-rational use of existing high quality human capital

2. the insufficiency of high quality human capital in the country.

These problems suggest that there is a need for an improvement in the encouragement of existing quality, high-level human capital as regards its precise realisation in this field, so as to show the direction of its future formation.

Analysis demonstrates that Bulgaria uses human capital of a relatively high level but not in a rational way with a view to the competitiveness of the economy, and with a low effect with respect to the participation of the country in high-technology international markets. At the same time, the potential for improving the efficiency of the use of human capital is not getting appreciably better. This situation looks more unfa-

5 Such as 1: expenditures on R\&D; 2: R\&D personnel; 3: human resources in R\&D - expenditures on education, science and technology graduates and students, share of foreign students, share of high-tech employment, etc; 4 : productivity and competitiveness - innovative and patent activity, share of high-tech exports, etc. 
vourable taking into account that Bulgaria is lagging in education in the field of science and technology, where qualified specialists are prepared for the needs of middle- and high-technology sectors and production, as well as for the requirements of R\&D.

One peculiarity which is outlined in this study is the increase in employment in sectors and branches that use lower-skilled labour. This means that there is a higher demand for and use of human capital of a lower level and quality. Such a trend could lead to the creation of unfavourable conditions for the future formation and status of human capital, as well as for the increase in the competitiveness of the economy.

A lagging behind may be observed in the use of human capital in a purely quantitative respect (indicative of which are the differences in the rates of employment and unemployment compared to the European average), as well as in the qualitative arena. For example: there is an imbalance between education for professions and demand on the labour market; there are also discrepancies between educational attainment and demand for labour, as well as between the quality and type of training and demand for labour; there are inappropriate practical training opportunities and experience for newly-forming specialists; and there are discrepancies in the training of specialists, both with and without higher education, and the demand for such specialists; etc.

There may also be observed an incomplete use of newly-formed human capital. The share of unemployed people looking for their first job after completion of school or university is also not insignificant and, at the same time, is increasing.

The uneven, and even decreasing, employment of the highly-educated labour force is unfavourable with regard to the extent and the direction of use of human capital. Indicative of the existing problems concerning the use of high-level human capital is also the lagging behind in the rates of economic activity and employment amongst the population, which has a high level of education compared to the European average.

These disproportions point, firstly, to the incomplete and non-rational use of human capital in the country; secondly, to the disparities and problems with its status; and thirdly, on the direction of its future formation.

The study also outlines that there is a certain unidirectionality between the demand for and supply of the low-skilled and lowly-educated labour force, i.e. of human capital of a relatively lower level and quality (indicative of which are the shares in the unemployed and amongst vacancies of people with such a characteristic). From the point of view of the balance on the labour market, this is a positive phenomenon. The reaching of a balance at a low level of skill, however, is not a positive phenomenon from the point of view of the development of human capital and of the building of the knowledge economy.

The outlined positive and negative phenomena and tendencies in the use (and in the status) of human capital in the country exert an influence on labour productivity, where the tendency is towards an increase during the last few years. 
Figure 13 - Labour productivity in Bulgaria* $(E U-27=100)$

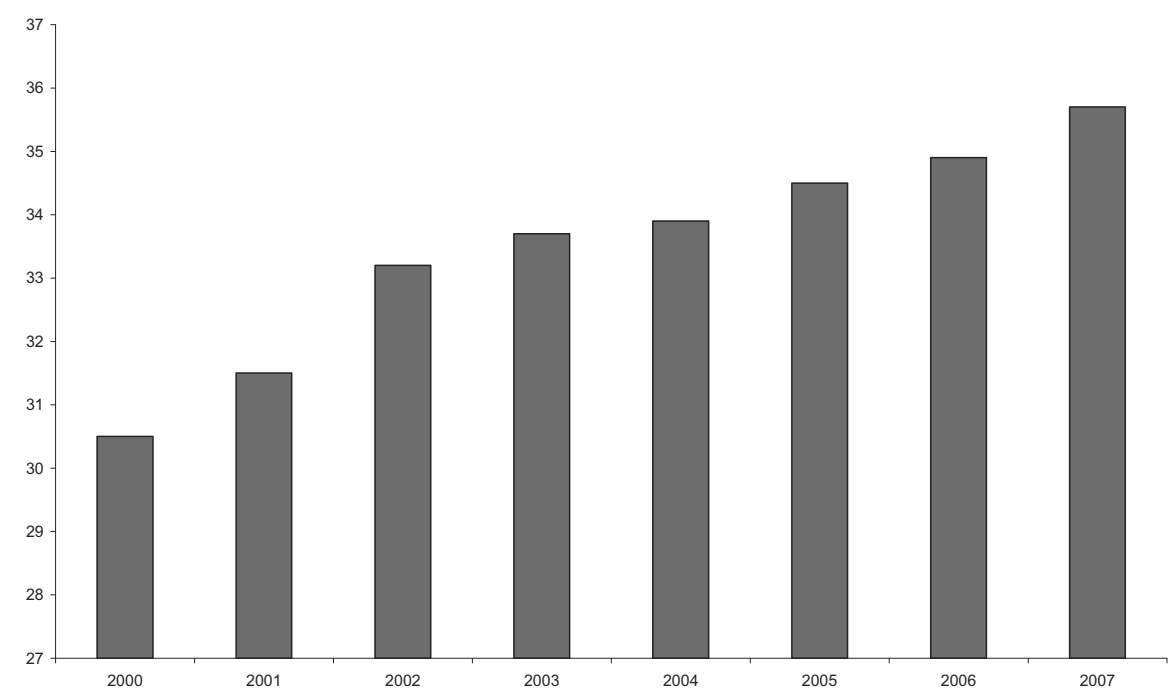

* GDP (in PPS) per person employed

Source: Eurostat

Despite this, Bulgaria significantly lags behind the average level for Europe. Labour productivity per person employed in the country is little higher than one-third of the average European indicator. The premises for this are problems with the formation, status and use of human capital, as well as problems with insufficient investment activity and the direction of the country's technological development.

\section{Directions for the development of human capital}

Based on the methodology of the study, which takes into account the complex relations and interdependences between the formation, status and use of human capital, a general conclusion could be made: policy for the development of human capital needs to be complex and directed towards all the components of the cycle. (Health care, migration and, to some extent, demographic processes are not the subject of this study, but they are also important components of the cycle, as is shown in Chart 1 above.) Given the results of this analysis and the general conclusions regarding both the positive and the negative processes and phenomena, and taking into account the priorities and the requirement of the EU as well as the role of human capital for the future socio-economic development of the country, the main directions of a holistic policy for the future development of human capital in Bulgaria could be outlined. These are:

1. Maintenance of macroeconomic stability and of sustainable economic growth. This is the way to create the conditions for an increase in employment, i.e. for the fuller use of human capital. At the same time, the requirements for human capital and the 
motivation for maintaining, restoring and improving learning and skills become higher. Thirdly, better preconditions and greater resources and possibilities for the development of the system of education and training - where, to a great extent, human capital is formed - are created. Economic development also favours:

a) demographic processes - it is the basis for the improvement in living standards which provides the possibilities for an increase in the birth rate and improving the age structure of the population

b) migration processes - the increase in the possibilities of employment and for improvements in living standards sub-serves the retaining of emigration flows, as well as the returning of emigrants

c) health care - more favourable conditions are created for the development of a health care system and for the improvement of the health status of the population. A better health status of people premises the ability to accumulate and to apply their learning and skills.

2. Promotion of the development of middle- and high technology industry sectors. This is a way to increase the competitiveness of the economy and is also a possibility as regards quick and sustainable development. Thus, the conditions for the fuller use of human capital, especially of high quality, are created. On the other hand, requirements as regards the level and quality of human capital, with all the subsequent effects, increase.

3. Stimulation of the development of R\&D activities. This direction, towards technical, technological and scientific development, is key and not only because of the ambition to attain the main European goal - the building of the most competitive knowledge-based economy. The development of this sphere presumes the creation, dissemination and implementation of new high-quality learning; and determines the improvement of innovation and the competitiveness of the economy. Requirements for the formation, use and the attraction of high-quality human capital from outside the country are thus created.

4. Improvement of labour market policy towards the achievement of a better balance between the demand for and supply of learning and skills; as well as for the promotion of the acquisition, restoration and improvement of the learning and skills of employed and unemployed people.

5. Activation of the budgetary, taxation and credit policies which may assist, promote and stimulate the formation of human capital, the restoration and improvement of learning and skills, and the level and efficiency of the use of existing capital as well as the innovative, scientific and technological activities associated with that.

6. Targeting regional policy towards supporting the overcoming of the existing territorial imbalances in the formation, distribution and use of human capital in the country.

7. Development of migration policy in order to improve the positive and to restrict the negative effects of migration processes. This policy could play an important role in the attraction of human capital from outside the country, as well as for the return of the newly-forming and high-quality human capital which has left the country. The main contribution in this direction, however, is that of economic development and the improvement of living standards which may create the respective stimuli. 
8. Improvement of demographic policy regarding the promotion of births and the creation of potential for the formation of human capital.

9. Development of the health care system and policy for the maintenance of the health status of people at a high level, which will assist physical survival and the restoration of the limited and diminishing human resource of the country. At the same time, better conditions would be created for:

a) the formation of human capital - an improved health status favours the better apprehension and acquisition of knowledge

b) use of human capital - an improved health status furthers the better realisation and application of learning and skills.

10. Development and improvement of the education system and policy. Depending on this to a great extent is the formation, maintenance and development of human capital, as well as its use (the quality and the adequacy of education concerning the requirements of the economy predetermine the realisation of this capital).

The timely overcoming of the important problems outlined in this analysis concerning the formation of human capital within the sphere of education and training requires the imposition of rapid and sufficient measures and activities in the following main directions:

1. increasing the participation of the population in education

2. improving access to, and overcoming the social and territorial disparities in, education

3. improving the quality of education

4. increasing the level of correspondence between education for professions and the requirements of the labour market

5. increasing participation in lifelong learning. An important role in the achievement of these directions is retained by the improvement of the necessary conditions for the functioning and development of the education and training system - i.e. the financial, legislative and institutional support systems. 